\title{
Two Phase Immiscible Fluids Flow Through A Porous Media: Finite Volume Approach
}

\author{
Flomena Jeptanui ${ }^{1}$, Jacob Bitok ${ }^{2}$, Titus Rotich ${ }^{3}$ \\ ${ }^{1}$ Doctorate student, Department of Mathematics and Computer Science, School of science, University of Eldoret, Eldoret, \\ Kenya \\ ${ }^{2}$ Department of Mathematics and Computer Science, School of Science University of Eldoret, Eldoret, Kenya \\ ${ }^{2}$ Department of biological Science, School of Science Moi University, Eldoret, Kenya
}

DOI: 10.29322/IJSRP.11.12.2021.p12067

http://dx.doi.org/10.29322/IJSRP.11.12.2021.p12067

\begin{abstract}
The groundwater remains a major source of water supply throughout the ages and groundwater quality is becoming water source problem. This problem is driven by contaminant transport equation involving advection and dispersion flux. Contaminant flow through a porous media meets tortuosity effects hence hydrodynamic dispersion must be considered. The study considers leaked petroleum from a transporting pipeline considered here as contaminant, enters the ground and infiltrate into groundwater reservoirs, hence contaminating aquifers. Petroleum and its product are extremely harmful to the natural environment and are considered carcinogenic. Numerical finite volume method is used to solve the contaminant transport equation. Our aim is to determine the petroleum concentration dispersion vertically and horizontally and determination of horizontal distant for exploitation of uncontaminated groundwater after a given time. The temporal discretization employs the second order Crank-Nicolson scheme for diffusive phenomena and a second order explicit Adams-Bashforth scheme for advective terms. The vertical dispersion is faster than the horizontal dispersion from the obtained results.
\end{abstract}

Index Terms- Porous media, Contaminant, Finite Volume Method, Numerical Modeling

\section{INTRODUCTION}

$\mathrm{G}$ roundwater is the most valuable natural resource that supports life on planet earth. Water contamination is one of the most typical hydro-geological and environmental hazards. In many parts of the world, groundwater resources are under increasing threat from growing population demands, wasteful use and contamination. During the process of petroleum exploitation, refining, transportation and storage, a mixture of hydrocarbon may accidentally spills or leaks causing environmental contamination. In this study, we consider petroleum leakages from transporting pipeline as a contaminant. The leaked petroleum ends up in subsurface water and some infiltrate into groundwater reservoirs. According to study carried out by [1], benzene presents both in crude oil and gasoline has been identified as a causative agent of leukemia in humans. Its lowers white blood cells leading to immune suppression in human. Health studies conducted in oil-exposed communities in the Niger Delta region of Nigeria have reported an increased incidence of headaches, diarrhea, dizziness, anemia and respiratory problems [2]. Chronic exposure either by drinking water contaminated with petroleum may also lead to degenerative changes in liver, kidney and spleen. The human activities have heavily affected the natural fields, the most prominent adverse effect being the soil and ground water contamination with petroleum products. A large number of physical, chemical and microbial processes and properties of the media affect contaminant transport in the soil and the groundwater. Most of the groundwater contaminants are reactive in nature and they infiltrate through the vadoze zone, reach the water table and continue to percolate in the direction of groundwater flow. Therefore, it is essential to understand the transport process of contaminants through the subsurface porous media.

Constant deposition of petroleum product resulting mainly from car washing, refilling stations, leakages from pipelines and transportation trucks, has resulted to high accumulation of this substance in soil and water environment. To monitor the rate of petroleum product leakage to groundwater, mathematical approach will be used to determine the concentration at every stratum in the study area.

\section{DISPERSION OF PETROLEUM}

\subsection{Leakage of petroleum to soil and groundwater}

The earth surface is $75 \%$ covered by water, most of which is saline. According to the water encyclopedia [3] 3-5\% of the available total water is fresh. High percentage of freshwater exists as ice stored in polar region 
leaving a less percent as groundwater and surface water. The most valuable resource on any location on planet earth is the existence of groundwater. Majority of the world population uses groundwater in various ways including domestic and industrial. The quality of this resource faces deterioration from human activities. Furthermore, the pressure from climate change, economic activities and population growth has accelerated ground water degradation. A common source for groundwater contaminant is hydrocarbon. The contamination of soil and groundwater by petroleum has become an increasing concern in the recent past. The leakage occurs from various sources. Some sources releases relatively small amounts per individual leak but in total it contributes a significant amount. Other sources include oil tankers that leaks less frequently but have a potential to release large volume in one incident. The sources of petroleum waste can be divided into point and linear. The point sources are contaminants that are released to soil and water from a specific location such as leakage from corroded pipelines, underground fuel tanks and injection supplies. The linear sources release contaminant into the soil and water from railroad with leaking tanks, damaged vehicles. A common source for groundwater contamination is petroleum leaks from underground storage tanks which happen due to improper design, human error, accidents, or simply due to the natural aging and deterioration of the tank itself or its associated piping and fittings [4]. Depending on the volume of the leaked and subsurface properties, the petroleum may be trapped in the vadose zone. There is continuation of infiltration of petroleum for high leak volume reaching close to water table, where it moves laterally in the same direction as groundwater. The leaked petroleum here considered as the contaminant after an appreciable time would surely find their way into rivers, streams and groundwater, which serve as the major source of drinking water for most rural dwellers particularly in sub-Saharan Africa region, [5].

The studies carried out shows that workers exposed to petroleum hydrocarbons have adverse health symptoms such as headaches, eye and skin irritation and respiratory difficulties [6]. These toxic contains substance that are carcinogenic, mutagenic as well as harmful to ecosystem and vegetation. [7]. some of the studies have shown that chronic exposure to petroleum and its product can impair the immune system [8]. The study carried out in Niger Delta region of Nigeria on petroleum hydrocarbon contamination, it showed that the activities associated with petroleum exploration, production and transportation have contaminated the soil, groundwater and environmental degradation [9]. These health and environmental impact necessitated the need for this study to analyze the dispersion of petroleum after it has leaked for exploitation of uncontaminated groundwater.

Over the last three decades several researchers have model analytical solutions in one-dimensional problems for fluid flow through semi-infinite or finite porous media. [10], dealt with an ideal situation while studying the distribution of general contaminant in a porous media and the work of [11] elaborated more on the transport of chemical contaminant with simultaneous adsorption and first order decay. In their studies they included the attenuation effect due to adsorption, first order radio-active decay and/or chemical reactions.

The work of [12] analyzed the groundwater contaminant due to transient sources of pollution and presented analytical solutions to predict temporal and spatial distribution of concentration in 1D, 2D, and 3D fully saturated uniform porous media flow for a point, line or parallelepiped source in an isotropic porous medium. A 2D analytical solution for transport equation with time-dependent dispersion coefficients were examined [13]. The dispersion of pollutant in the planetary boundary layer was studied and presented an analytical solution for advection-diffusion equation to simulate the pollutant dispersion [14]. The researchers in [15] considered groundwater contaminant transport in a heterogeneous medium by assuming pore flow velocity to be a nondivergence free, unsteady and non stationary random function of space and time.

The work of [16] examined the transportation of contaminant from a point source in semi-infinite homogeneous porous medium and presented their 2D analytical solutions. The above work discussed more on general contaminant dispersion in a porous media but our study is skewed towards dispersion of petroleum as a contaminant.

\section{MATERIALS AND METHOD}

The infiltration of leaked contaminant comprises of transport and attenuation. The migration of contaminant are in two major steps namely migration from one point to another (advective) and dissipation of contaminant during the transport process (dispersion). The general differential equation of contaminant migration has been used in this study and finite volume method for the numerical model to be used in investigating the problem of petroleum contaminant dispersion. The contaminant transport equation given by

$$
\frac{\theta \partial C}{\partial t}=\theta\left(D_{x} \frac{\partial^{2} C}{\partial x^{2}}+D_{z} \frac{\partial^{2} C}{\partial z^{2}}\right)-\left(u_{x} \frac{\partial C}{\partial x}+u_{z} \frac{\partial C}{\partial z}\right)+\phi
$$

Where $\mathrm{C}$ is the contaminant concentration, $\mathrm{x}, \mathrm{z}$ are distance variable, porosity, $\mathrm{D}$ - hydrodynamic dispersion and $\mathrm{u}, \mathrm{w}$ are the contaminant fluxes in $\mathrm{x}$ and $\mathrm{z}$ direction respectively. The contaminant velocity in porous media is under the influence of ground water potential head h. From the Darcy's law contaminant velocity can be expressed as

$$
u_{x}=u_{z}=-\frac{K}{\theta} \frac{\partial h}{\partial l}
$$


K- Soil conductivity dependant on soil type and $l$ is the length.

With the assumption that the porous media is sandy, the model parameters are defined as in table 1

\begin{tabular}{|c|c|}
\hline Parameters & Value \\
\hline Soil porosity & 0.35 \\
\hline Soil conductivity & 0.0004-0.000006 \\
\hline Diffusion coefficient $\quad \mathrm{m}^{2} / \mathrm{s}$ & 0.0000007 \\
\hline Longitudinal dispersity & 4.7 \\
\hline Transversal dispersity $\mathrm{m} / \mathrm{s}$ & 2 \\
\hline Time of investigation day & 365 \\
\hline
\end{tabular}

It is assumed that the contaminant source leaking from a pipeline is located at the top of the saturated sandy soil surface. The finite volume method has been used in this study with help of Matlab software

\section{NUMERICAL METHOD}

\subsection{Finite Volume Discretization (FVM)}

The solution of the partial differential equation (1) will be obtained numerically by employing the finite volume method. Adams-Bashforth Differencing was chosen to obtain the solution equation (3). The solution domain consists of a space and time domain. The time discretization required for fluid flow problems is broken into a set of equal time steps written as $\Delta t$.

Discretization of space requires the subdivision of the domain into a number of discrete volumes as shown in figure 3.1. Each volume will have a representative value located at the centre. For one dimension, the cells are numbered from 1 to $\mathrm{N}$. The cell point will be located at $\mathrm{i}$ and having neighbors $\mathrm{i}-1$ and $\mathrm{i}+1$ and the interfaces with those neighboring volume being $i-\frac{1}{2}$ and $i+\frac{1}{2}$. The boundaries (or faces) of control volumes are positioned mid-way between adjacent nodes. Thus each node is surrounded by a control volume or cell. It is common practice to set up control volumes near the edge of the domain in such a way that the physical boundaries coincide with the control volume boundaries.

We will illustrate the position of the control volume using 1D as shown in figures 3.1 and 3.2

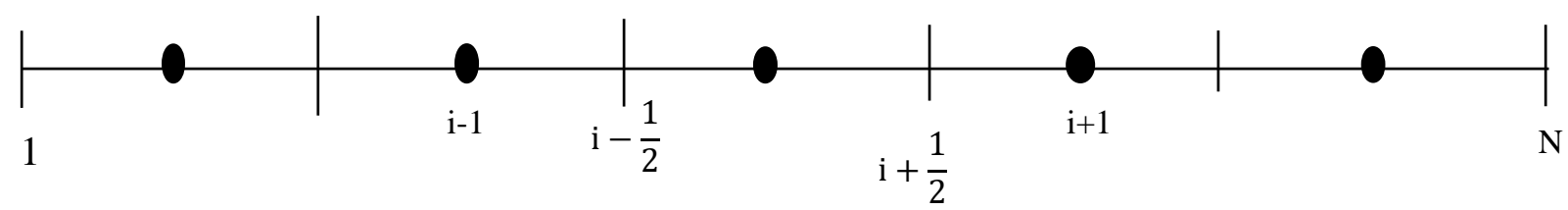

Figure 4.1: Discretization of 1D into domain Cartesian finite volume 


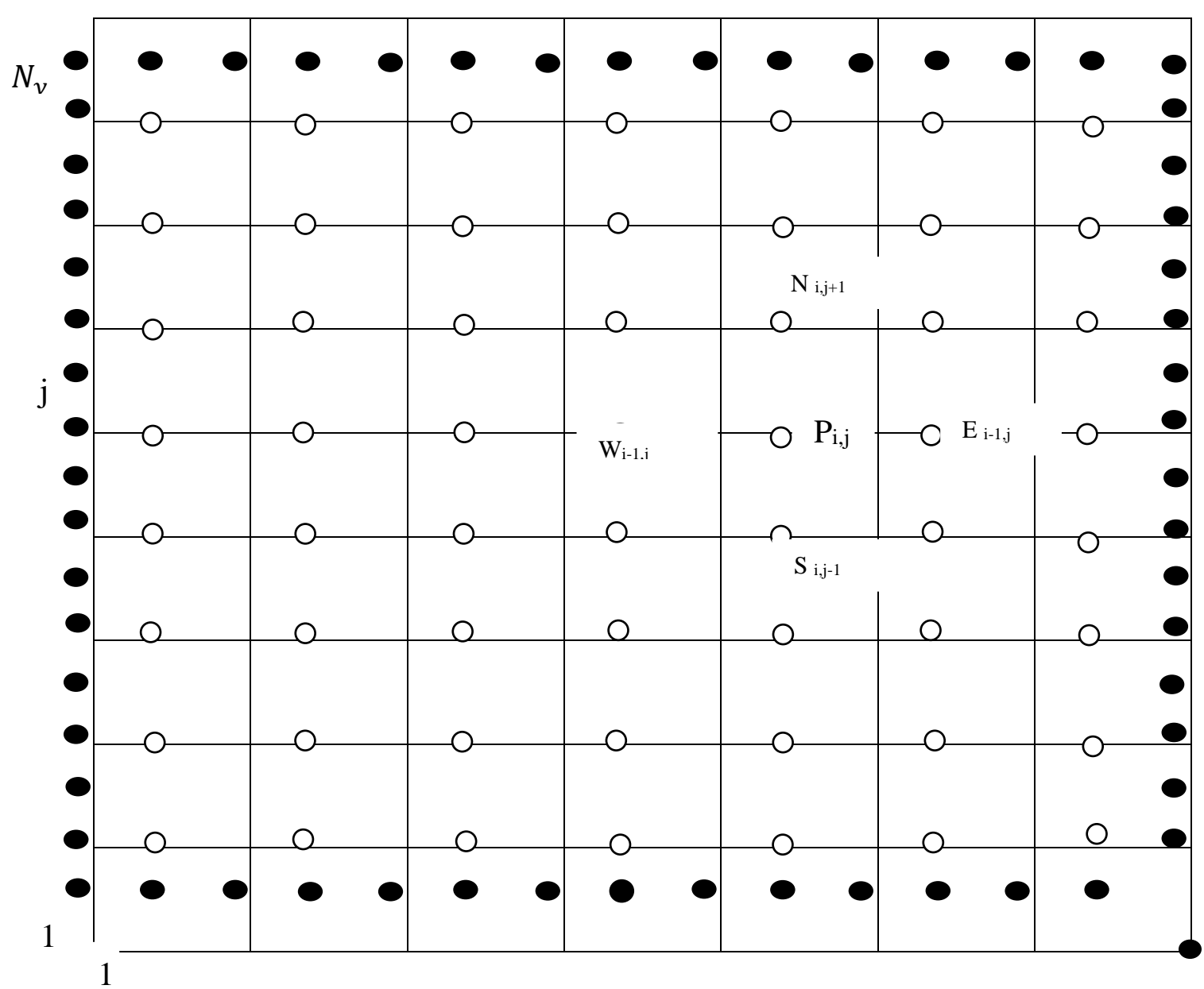

Figure 4.2 The discretization of 2D domain into Cartesian finite volume

In FVM, compass notations are used when referring to the cell neighborhoods. The point $\mathrm{P}$ on the mesh signifies the cell upon which our equation is being discretized. The immediate neighbors of point $\mathrm{P}$ are $\mathrm{E}, \mathrm{W}, \mathrm{N}$ and $\mathrm{S}$ to the East, West, North and South respectively in the $\mathrm{x}-\mathrm{Z}$ axis. We use capital letters to signify the value at the centre of the neighboring cell and small letters to signify the value at the interface between two cells.

The advection term, equation (1) is interpolated linearly between faces $\mathrm{E}$ and $\mathrm{W}$ about point $\mathrm{P}$ using Central Differencing scheme (CD) to obtain

$\int_{w}^{e} u_{x} \frac{\partial C}{\partial x} d x+\int_{s}^{n} u_{w} \frac{\partial C}{\partial z} d z \approx(u)_{e} \frac{\left(C_{E}+C_{P}\right)}{2}-(u)_{w} \frac{\left(C_{P}+C_{W}\right)}{2}+(u)_{n} \frac{\left(C_{N}+C_{P}\right)}{2}-(u)_{s} \frac{\left(C_{P}+C_{S}\right)}{2}$

$\mathrm{CD}$ is second accurate even on a non uniform meshes.

\subsection{Crank-Nilcoson scheme}

The Crank-Nilcoson method is an implicit second order both in time and space and is unconditionally stable. Equation is integrated from $\mathrm{t}$ to $t+\Delta t$, where in this scheme values averages of $\mathrm{t}$ and $t+\Delta t$ are used. The Crank-Nilcoson discretization for the viscous term can be written as

$$
\frac{1}{\Delta t} \int_{t}^{t+\Delta t} \theta D_{e}\left\{\left(\frac{C_{E}-C_{P}}{(\delta x)_{e}}\right)-\left(\frac{C_{p}-C_{W}}{(\delta x)_{w}}\right)\right\} d t \approx \theta\left(D_{e} \frac{C_{E}^{n+1}-C_{P}^{n+1}}{2 \delta x_{e}}\right)-\left(D_{e} \frac{C_{P}^{n}-C_{W}^{n}}{2 \delta x_{W}}\right)+\theta\left(D_{w} \frac{C_{P}^{n+1}-C_{W}^{n+1}}{2 \delta x_{W}}\right)-\left(D_{w} \frac{C_{P}^{n}-C_{W}^{n}}{2 \delta x_{W}}\right)
$$

\subsection{Adams-Bashforth Differencing}

This scheme extrapolate advective terms from previous time step in an explicit manner and handles diffusive terms implicitly using Crank-Nicolson second order scheme.

The integration of advective terms in equation (1) from time step $n$ to $n+1$ is approximated by $\frac{1}{\Delta t} \int_{n}^{n+1} \rho u C d t \approx \frac{3}{2}\left(\rho u_{x} C\right)^{n}-\frac{1}{2}\left(\rho u_{x} C\right)^{n-1}$ 
The value of the scalar $\mathrm{C}$ at the cell face is approximated by using the central differencing scheme, hence the advective term becomes

$$
\begin{aligned}
& \frac{1}{\Delta t} \int_{t}^{t+\Delta t} \rho u_{x}\left((C)_{e}-(C)_{w}\right) d t+\rho u_{z}\left((C)_{n}-(C)_{s}\right) d t \approx \rho u_{x}\left(\frac{3}{2} C_{e}^{n}-\frac{1}{2} C_{e}^{n-1}\right)-\rho u_{z}\left(\frac{3}{2} C_{n}^{n}-\frac{1}{2} C_{s}^{n-1}\right) \\
\approx & \rho u_{\mathrm{x}}\left(\frac{3}{4}\left(\mathrm{C}_{\mathrm{P}}^{\mathrm{n}}+\mathrm{C}_{\mathrm{E}}^{\mathrm{n}}\right)-\left(\mathrm{C}_{\mathrm{P}}^{\mathrm{n}}+\mathrm{C}_{\mathrm{W}}^{\mathrm{n}}\right)-\frac{1}{4}\left(\left(\mathrm{C}_{\mathrm{P}}^{\mathrm{n}-1}+\mathrm{C}_{\mathrm{E}}^{\mathrm{n}-1}\right)-\left(\mathrm{C}_{\mathrm{P}}^{\mathrm{n}-1}+\mathrm{C}_{\mathrm{W}}^{\mathrm{n}-1}\right)\right)+\rho \mathrm{u}_{\mathrm{z}}\left(\frac{3}{4}\left(\mathrm{C}_{\mathrm{P}}^{\mathrm{n}}+\mathrm{C}_{\mathrm{N}}^{\mathrm{n}}\right)-\left(\mathrm{C}_{\mathrm{P}}^{\mathrm{n}}+\mathrm{C}_{\mathrm{S}}^{\mathrm{n}}\right)-\right.\right. \\
& \frac{1}{4}\left(\left(\mathrm{C}_{\mathrm{P}}^{\mathrm{n}-1}+\mathrm{C}_{\mathrm{N}}^{\mathrm{n}-1}\right)+\left(\mathrm{C}_{\mathrm{P}}^{\mathrm{n}-1}+\mathrm{C}_{\mathrm{S}}^{\mathrm{n}-1}\right)\right)
\end{aligned}
$$

For diffusive terms we employ the Crank-Nicolson Scheme as given in equation (4). Substituting equations (3),(4) and (6) in (1) to obtain

$$
\begin{aligned}
& \frac{1}{\Delta \mathrm{t}} \int_{\mathrm{t}}^{\mathrm{t}+\Delta \mathrm{t}} \mathrm{D}_{\mathrm{e}}\left\{\left(\frac{\mathrm{C}_{\mathrm{E}}-\mathrm{C}_{\mathrm{P}}}{(\delta \mathrm{x})_{\mathrm{e}}}\right)-\left(\frac{\mathrm{C}_{\mathrm{P}}-\mathrm{C}_{\mathrm{W}}}{(\delta \mathrm{x})_{\mathrm{w}}}\right)\right\} \mathrm{dt} \\
& \approx\left(\mathrm{D}_{\mathrm{e}} \frac{\mathrm{C}_{\mathrm{E}}^{\mathrm{n}+1}-\mathrm{C}_{\mathrm{P}}^{\mathrm{n}+1}}{2 \delta \mathrm{x}_{\mathrm{e}}}\right)-\left(\mathrm{D}_{\mathrm{e}} \frac{\mathrm{C}_{\mathrm{P}}^{\mathrm{n}}-\mathrm{C}_{\mathrm{W}}^{\mathrm{n}}}{2 \delta \mathrm{x}_{\mathrm{W}}}\right)+\left(\mathrm{D}_{\mathrm{w}} \frac{\mathrm{C}_{\mathrm{P}}^{\mathrm{n}+1}-\mathrm{C}_{\mathrm{W}}^{\mathrm{n}+1}}{2 \delta \mathrm{x}_{\mathrm{W}}}\right)-\left(\mathrm{D}_{\mathrm{w}} \frac{\mathrm{C}_{\mathrm{P}}^{\mathrm{n}}-\mathrm{C}_{\mathrm{W}}^{\mathrm{n}}}{2 \delta \mathrm{x}_{\mathrm{w}}}\right) \\
& \begin{array}{l}
\rho \frac{\Delta x}{\Delta t}\left(C_{P}^{n+1}-C_{P}^{n}\right) \\
\left.\left(C_{N}^{n}-2 C_{P}^{n}+C_{\mathrm{S}}^{\mathrm{n}}\right)\right)
\end{array}
\end{aligned}
$$

Integrating the transient term in time

$\frac{1}{\Delta t} \int_{t}^{t+\Delta t} \theta \frac{\partial(\rho C)}{\partial t} \Delta x d t=\theta \rho \frac{\Delta x}{\Delta t}\left(C_{P}^{n+1}-C_{P}^{n}\right)$

The source term is represented in the linearized form $\phi=\phi_{u}+\phi_{p} C_{p}$.

Using the finite volume discretization (4), (7) and (8) in (1) to obtain the discretized transport equation $\theta \rho \frac{\Delta x}{\Delta t}\left(C_{P}^{n+1}-C_{P}^{n}\right)=\frac{1}{2} \theta \mathrm{D}_{\mathrm{x}}\left(\left(C_{E}^{n+1}-2 C_{P}^{n+1}+C_{W}^{n+1}\right)-\left(C_{E}^{n}-2 C_{P}^{n}+\mathrm{C}_{\mathrm{W}}^{\mathrm{n}}\right)\right)+\frac{1}{2} \theta \mathrm{D}_{\mathrm{z}}\left(\left(C_{N}^{n+1}-2 C_{P}^{n+1}+\right.\right.$ $\left.\left.C_{S}^{n+1}\right)-\left(C_{N}^{n}-2 C_{P}^{n}+C_{\mathrm{S}}^{\mathrm{n}}\right)\right)-\left[\rho \mathrm{u}_{\mathrm{x}}\left(\frac{3}{4}\left(\mathrm{C}_{\mathrm{E}}^{\mathrm{n}}-\mathrm{C}_{\mathrm{W}}^{\mathrm{n}}\right)-\frac{1}{4}\left(\left(\mathrm{C}_{\mathrm{E}}^{\mathrm{n}-1}-\mathrm{C}_{\mathrm{W}}^{\mathrm{n}-1}\right)\right)+\rho \mathrm{u}_{\mathrm{z}}\left(\frac{3}{4}\left(\mathrm{C}_{\mathrm{N}}^{\mathrm{n}}-\mathrm{C}_{\mathrm{S}}^{\mathrm{n}}\right)-\frac{1}{4}\left(\left(\mathrm{C}_{\mathrm{N}}^{\mathrm{n}-1}-\right.\right.\right.\right.\right.$ $\left.\left.\left.\mathrm{C}_{\mathrm{S}}^{\mathrm{n}-1}\right)\right)\right]+\phi_{\mathrm{u}}+\phi_{\mathrm{p}} C_{p}^{n+1}$

Which on factorizing we obtain

$\left(\rho \frac{\Delta x}{\Delta t}+\theta \mathrm{D}_{\mathrm{x}}+\theta \mathrm{D}_{\mathrm{z}}+\phi_{\mathrm{p}}\right) C_{p}^{n+1}=\left(\rho \frac{\Delta x}{\Delta t}+\theta \mathrm{D}_{\mathrm{x}}+\theta \mathrm{D}_{\mathrm{z}}\right) C_{P}^{n}+\frac{1}{2} \theta \mathrm{D}_{\mathrm{x}}\left(C_{E}^{n+1}+C_{W}^{n+1}\right)+\frac{1}{2} \theta \mathrm{D}_{\mathrm{z}}\left(C_{N}^{n+1}+C_{S}^{n+1}\right)-$ $\left(\frac{3}{4} \rho u_{\mathrm{x}}\left(\mathrm{C}_{\mathrm{E}}^{\mathrm{n}}-\mathrm{C}_{\mathrm{W}}^{\mathrm{n}}\right)+\frac{3}{4} \rho \mathrm{u}_{\mathrm{z}}\left(\mathrm{C}_{\mathrm{N}}^{\mathrm{n}}-\mathrm{C}_{\mathrm{S}}^{\mathrm{n}}\right)-\frac{1}{4} \rho \mathrm{u}_{\mathrm{x}}\left(\mathrm{C}_{\mathrm{E}}^{\mathrm{n}-1}-\mathrm{C}_{\mathrm{W}}^{\mathrm{n}-1}\right)-\frac{1}{4} \rho \mathrm{u}_{\mathrm{z}}\left(\mathrm{C}_{\mathrm{N}}^{\mathrm{n}-1}-\mathrm{C}_{\mathrm{S}}^{\mathrm{n}-1}\right)\right)+\phi_{\mathrm{u}}$ $\Rightarrow>$ $a_{P} C_{P}^{n+1}=a_{E}\left(C_{E}^{n+1}+C_{W}^{n+1}\right)+a_{B}\left(C_{N}^{n+1}+C_{S}^{n+1}\right)+a_{P} C_{P}^{n}+b_{E}\left(\mathrm{C}_{\mathrm{E}}^{\mathrm{n}}-\mathrm{C}_{\mathrm{W}}^{\mathrm{n}}\right)+b_{B}\left(\mathrm{C}_{\mathrm{N}}^{\mathrm{n}}-\mathrm{C}_{\mathrm{S}}^{\mathrm{n}}\right)+b_{A}\left(\mathrm{C}_{\mathrm{E}}^{\mathrm{n}-1}-\right.$ $\left.\mathrm{C}_{\mathrm{W}}^{\mathrm{n}-1}\right)+b_{D}\left(\mathrm{C}_{\mathrm{N}}^{\mathrm{n}-1}-\mathrm{C}_{\mathrm{S}}^{\mathrm{n}-1}\right)+\phi_{\mathrm{u}}$

Where

$a_{E}=\frac{1}{2} \theta \mathrm{D}_{\mathrm{x}}, a_{B}=\frac{1}{2} \theta \mathrm{D}_{\mathrm{z}}, a_{P}=\rho \frac{\Delta x}{\Delta t}+\theta \mathrm{D}_{\mathrm{x}}+\theta \mathrm{D}_{\mathrm{z}}+\phi_{\mathrm{p}}, b_{E}=\frac{3}{4} \rho \mathrm{u}_{\mathrm{x}}, b_{B}=\frac{3}{4} \rho \mathrm{u}_{\mathrm{z}}, b_{D}=-\frac{1}{4} \rho \mathrm{u}_{\mathrm{z}}, b_{A}=-\frac{1}{4} \rho \mathrm{u}_{\mathrm{x}}$

\subsection{Stability criterion}

The convergence of simulated results is achieved by determination of stability criterions. In this study we use the following criterions:

i. Courant Condition: This is the product of fluid velocity $v$ and $\Delta \mathrm{t}$ is equal to or less than $\Delta \mathrm{x}$. The Courant

Condition can be written mathematically as (11)

$C_{o x}=\left|\frac{\Delta t \cdot u_{x}}{\Delta x}\right| \leq 1 \quad$ Flow of water along the x-direction

$C_{O Z}=\left|\frac{\Delta t \cdot u_{z}}{\Delta z}\right| \leq 1 \quad$ Flow of water along the y-direction

ii. Neumann criteria: this criterion describes the relationship between hydrodynamics dispersion with spatial component. The Neumann Criterion is mathematically formulated as [10]

$$
\frac{\mathrm{D}_{\mathrm{x}} \cdot \Delta \mathrm{t}}{(\Delta \mathrm{x})^{2}}+\frac{\mathrm{D}_{\mathrm{z}} \cdot \Delta \mathrm{t}}{(\Delta \mathrm{z})^{2}} \leq 0,5
$$

iii. Peclet Number (Pe): This is the ratio between advection to hydrodynamics dispersion and mathematically can be formulated as [10]

$$
P e_{x}=\frac{v_{x} \Delta x}{D_{x}} \leq 2 \quad \text { Flow of water along the } \mathrm{x} \text {-direction }
$$




$$
P e_{z}=\frac{v_{z} \Delta x}{D_{z}} \leq 2 \text { Flow of water along the y-direction }
$$

\subsection{Model setup}

Once the models equations have been transformed to discrete equations, the next step to be followed is the setup of the model. At this point the physical parameters are determined, more so the porous media properties and configurations. The design of the model is a simple rectangle with confined condition at the bottom side.

Impermeable side. Neumann boundary

condition $: \frac{\partial C}{\partial z}=0$

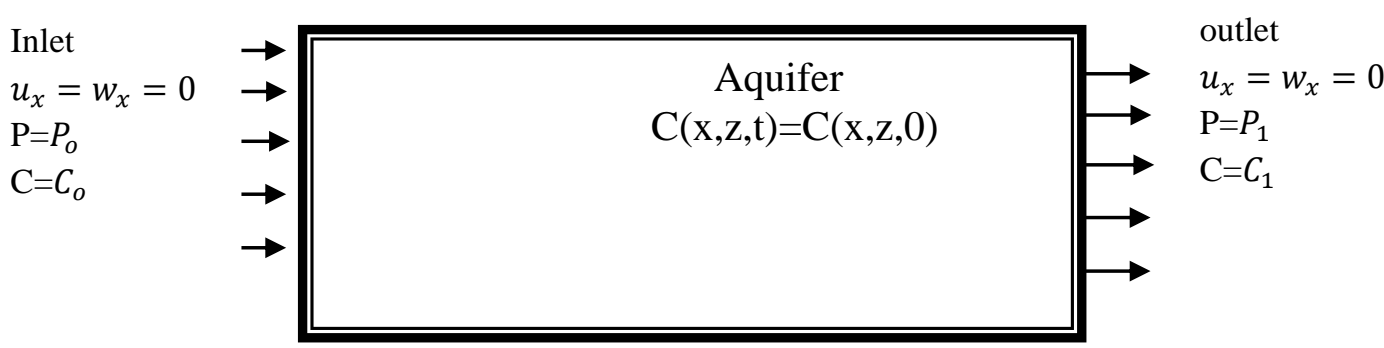

Figure 1: Boundary conditions Impermeable boundary. Neumann

$$
\text { boundary condition }: \frac{\partial C}{\partial z}=0
$$

The following are simple explanati

i. Dirichlet boundary condition: This is where the primary variables values are constant along the model boundary [17], hence the contaminant concentration (C) have a constant value.

ii. Neumann boundary condition: It represents the variables conditions on the perpendicular model boundary [17]. These are related to contaminant and groundwater flux across the model boundaries. The top and bottom is impermeable layer, simulating the model into a confined condition. The following conditions holds:

$\frac{\partial C}{\partial z}=0$

The initial conditions for the study

And boundary conditions

$$
\begin{gathered}
u(x, 0)=w(z, 0)=0=u(x, z) \\
C(0, z)=C_{o}, C(x, z)=C_{1}
\end{gathered}
$$

\section{RESULTS AND DISCUSSION}

A computer program for the finite volume method is developed for simulation of the dispersion of petroleum contaminant as per the aim of this study. Results are generated using Matlab software chosen for this study. The dispersion of the leaked petroleum with emphasis on time factor around one year is concluded and presented in Figure 2. From the study, it is concluded that petroleum dispersion pattern is regarded as both horizontal and vertical. The depth of petroleum penetration vertically has been plotted in figures 3 to 5 . It has been observed that the vertical penetration is affected by the permeability factor of porous media. 

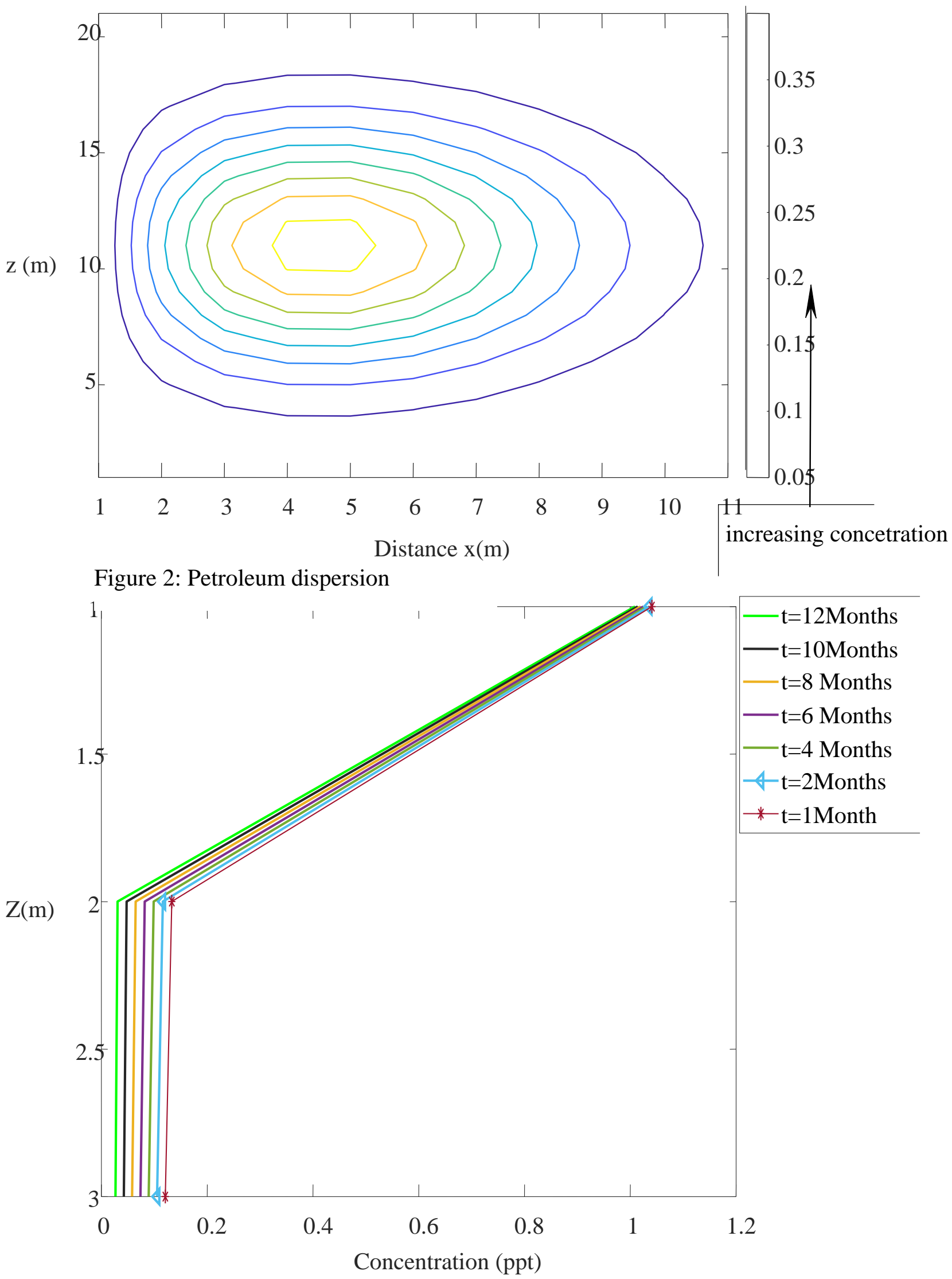

Figure 3: Values of vertical petroleum concentration when $K=10^{\wedge}-4(\mathrm{~m} / \mathrm{s})$ 


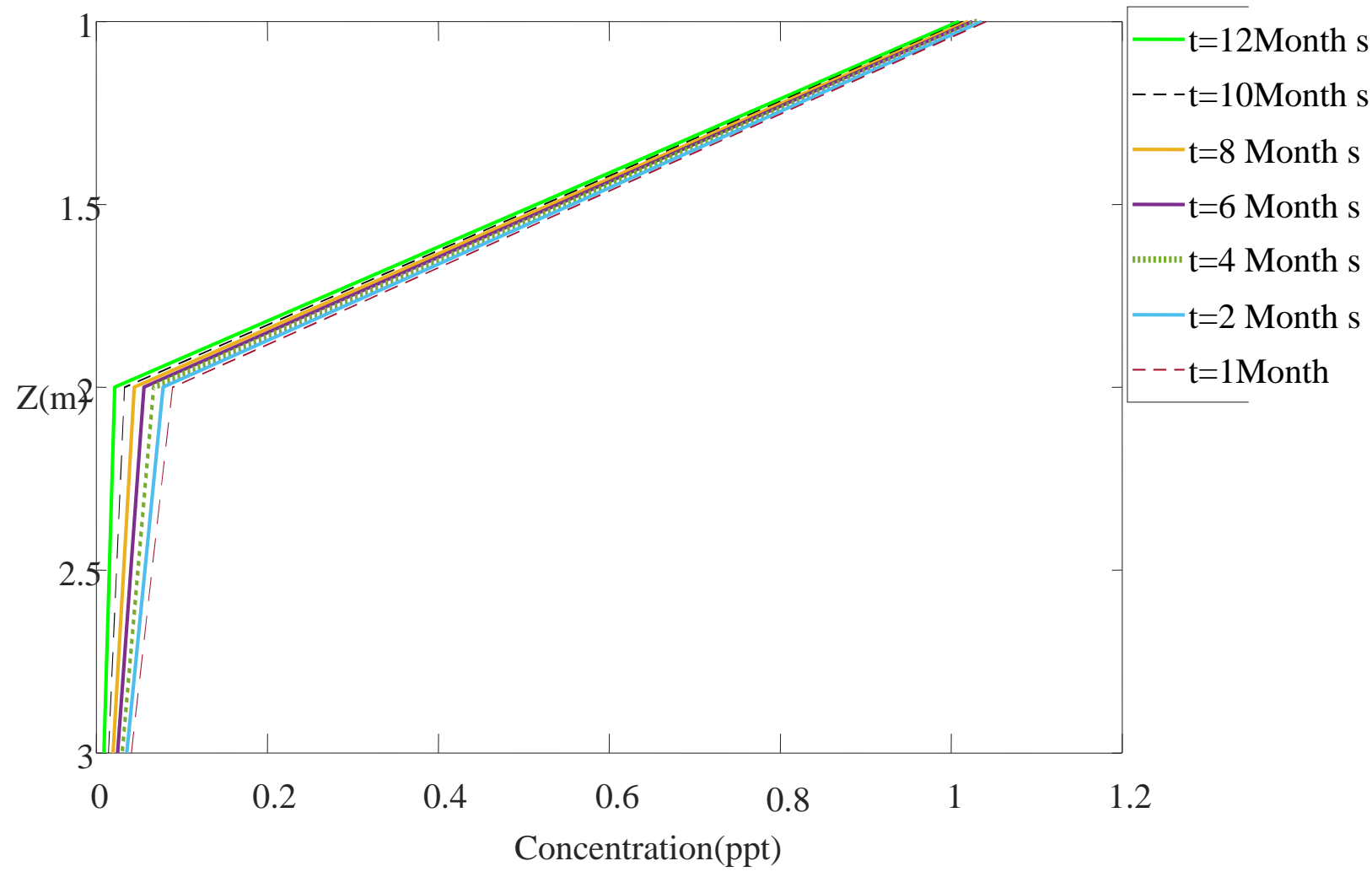

Figure 4: Values of petroleum concentration when $K=10^{\wedge}-5(\mathrm{~m} / \mathrm{s})$

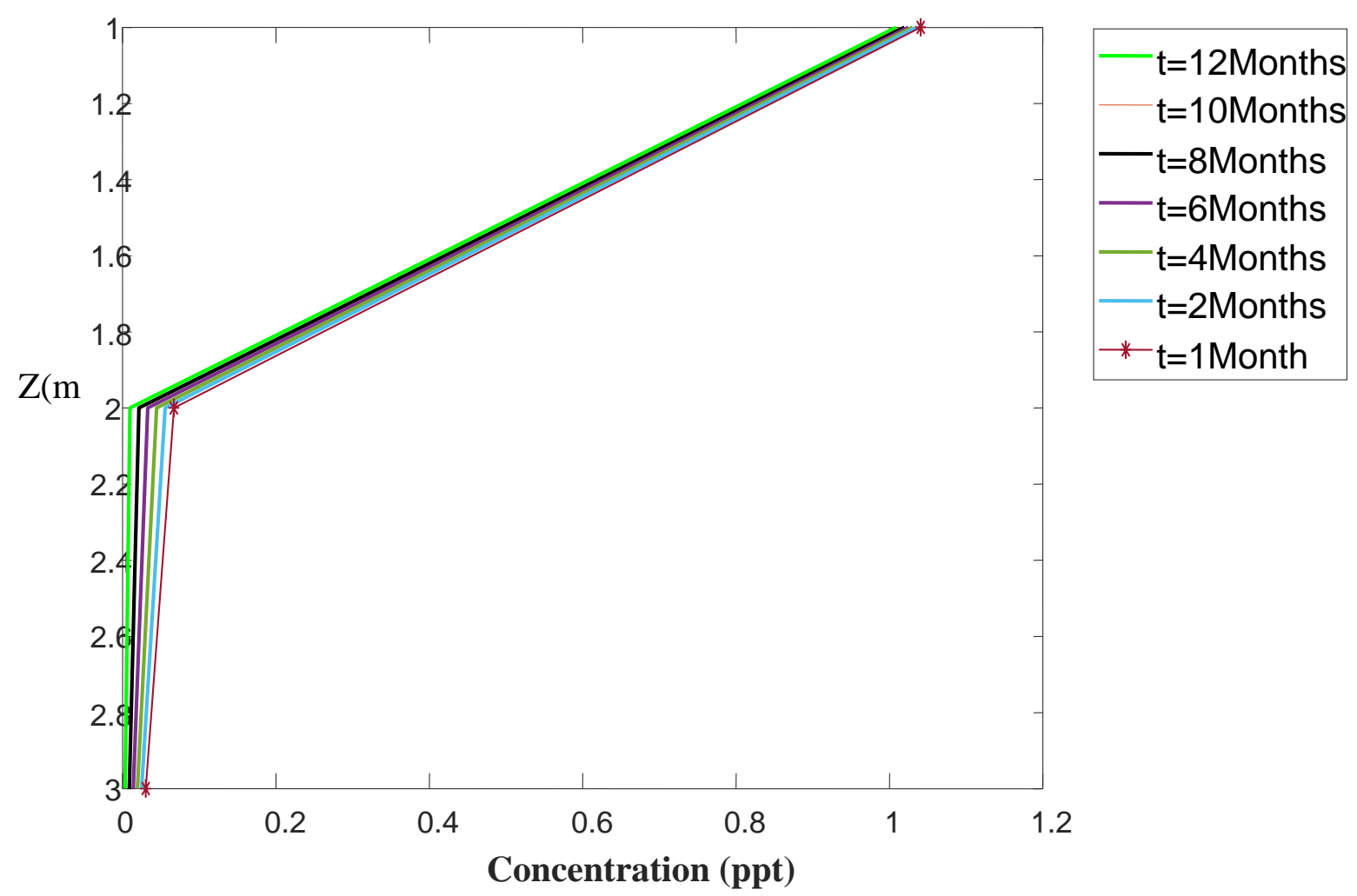

Figure 5: Values of vertical petroleum concentration when $K=10^{\wedge}-6(\mathrm{~m} / \mathrm{s})$

The horizontal petroleum dispersion has been plotted in figure 6 . It can be observed that the petroleum concentration near the leaked point is more than 10 times greater than when it is about $3 \mathrm{~m}$ away from leaking 
point on sides, implying that the horizontal petroleum dispersion can be monitored and control, compared to vertical dispersion of petroleum contaminant.

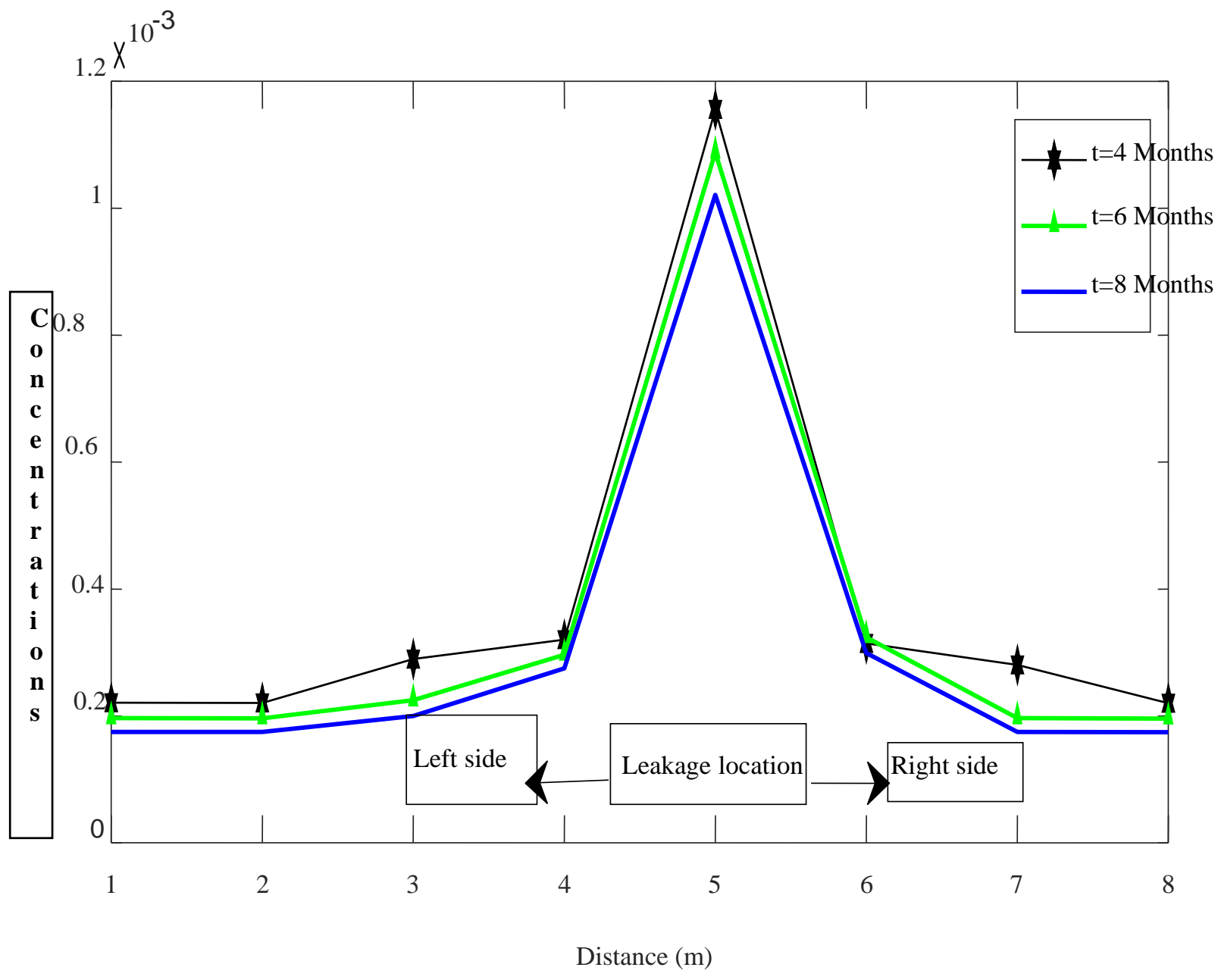

Figure 6: Values of horizontal petroleum concentration

\section{CONCLUSION}

This study presents Finite Volume Method to solve the advection-dispersion equation with longitudinal and transverse dispersion for describing the two dimensional transport of petroleum contaminant in a homogeneous porous media. The study indicates that the dispersion of contaminant is not uniform but decrease as we move away from leaked point along either direction.

The petroleum dispersion in a saturated porous has been evaluated. Most of the studies involved fluid flow through porous unsaturated or dry soil condition. Results from the current study show that the vertical dispersion is faster than horizontal dispersion in saturated media. The proposed numerical solution can be helpful to hydrologist in monitoring and evaluating contaminants in a contaminated field where the contaminant can be removed to minimize groundwater contaminations. 


\section{REFERENCES}

[1] Kponee, K.Z, Chiger, A., Kakulu, I.I.,Vorhees. D \& Helger.B.W. (2015), Petroleum contaminated water and health symptoms: a cross-sectional pilot study in a rural Nigerian community. Environ Health 14, (86). https://doi.org/10.1186/s12940-015-0073-0

[2] Kponee, K.Z, Nwanyi-Enwevem, J.C., Fu, X, Kakulu, I.I, Weisskof, M.G., \& Jia, C. (2018). Elevated indoor volatile organic compound exposure in the Niger Delta Region of Nigeria. International Journal Environment resident Public Health 15(9). https://doi.org/10.3390/ijerph-15091949

[3] Van der Leeden, F., Troise, F.L. and D.K. Todd, (1990.). The Water Encyclopedia, 2nd ed., Lewis Publishers, Chelsea, MI.

[4] Al-Suwaiyan, M.S., Bashir, K., Aiban, S.A. and Ishaq, A.M.,( 2002) Analytical model to quantify crude oil spills in sandy layered aquifers. Journal of Environmental Engineering, ASCE, 128(4), pp. 320-326.

[5] Kiptum, C.K., \& Ndambuki, J.M. (2012). Well water contamination by pit latrines. A case study of langas. International Journal of water resources environmental engineering 4(2), 35-43.

[6] Aguilera, F., J. Méndez, E. Pásaro, and B. Laffon,(2010). "Review on the effects of exposure to spilled oils on human health," Journal of Applied Toxicology, 30 (4). 291-301.

[7] Diary A M A, Twana,O.A, Peshawa M A and Nadhir A A(2019). Soil and Groundwater Pollution Assessment and Delineation of Intensity Risk Map in Sulaymaniyah City, NE of Iraq. Water(11)02158

[8] Bahadar, H., S. Mostafalou, and M. Abdollahi,(2010). "Current understandings and perspectives on non-cancer health effects of benzene: A global concern," Toxicology and Applied Pharmacology, 276 (2). 83-94, 2014 (1). 133-148, 2010.

[9] Aniefiok E. Ite1, Thomas A. Harry, Clement O. Obadimu1, Ekpedeme R. Asuaiko, Iniemem J. Inim(2018). Petroleum Hydrocarbons Contamination of Surface Water and Groundwater in the Niger Delta Region of Nigeria. Journal of Environment Pollution and Human Health, Vol. 6, No. 2, 51-61

[10] Notodarmojo,S.(2005).Pencemaran Tanah dan Air Tanah. Bandung: Penerbit ITB.

[11] Van Genuchten, M. Th. (1981). Analytical solutions for chemical transport with simultaneous adsorption, zero-order production and first order decay. Journal of Hydrology, 49(3-4), 213-233.

[12] Prakash, A. (1984). Groundwater contaminant due to transient sources of pollution. Journal of Hydraulic Engineering, 110(1), $1642-1658$.

[13] Aral, M.M.; and Liao, B. (1996). Analytical solutions for two-dimensional transport equation with time-dependent dispersion coefficients. Journal of Hydrologic Engineering, 1(1), 20-32.

[14] Wortmanna, S.,Vilhena, M.T., Moreirab, D.M.; and Buske, D. (2005). A new analytical approach to simulate the pollutant dispersion in the PBL. Atmospheric Environment, 39(12), 2171-2178

[15] Sirin, H. (2006). Ground water contaminant transport by non-divergence free, unsteady and non-stationary velocity fields. Journal of Hydrology, 330(3-4), 564572.

[16] Yadav,R.R, and kumar,D.J,(2011). Two-dimensional analytical solutions for point source contaminants transport in semi-infinite homogeneous porous medium. Journal of Engineering Science and Technology Vol. 6, No. 4, 459- 468.

[17] Guo, W., \& Langevin, C.(2002). User's Guide to Seawat: A Computer Program for Simulation of Three-Dimensional Variable Density Ground-Water Flow. Florida: U.S Geological Survey.

[18] Marino, M.A. (1974). Distribution of contaminants in porous media flow. Water Resources Research, 10(5), 1013-1018.

\section{AUTHORS}

First Author - Flomena Jeptanui, Doctorate student, Department of Mathematics and Computer Science, School of science, University of Eldoret, Eldoret, Kenya

Second Author - Jacob Bitok, Department of Mathematics and Computer Science, School of Science University of Eldoret, Eldoret, Kenya

Third Author - Titus Rotich, Department of biological Science, School of Science Moi University, Eldoret, Kenya

Corresponding Author E-mail:flomenamaiyo@gmail.com 